\title{
PARA UMA ECONOMIA POLÍTICA DA ÁGUA: CONTRIBUIÇÃO AO DEBATE SOBRE SOCIEDADE, TECNOLOGIA E MEIO AMBIENTE ${ }^{1}$
}

For a political economy of water: contribution to the debate on society, technology and the environment

Ivo Marcos Theis

"Quando a água desaparecer que será do homem, que será das coisas, dos verdes e bichos? Que será de Deus?"

(Mário Quintana)

\section{Resumo}

O objetivo central nesse artigo é analisar a problemática da água no contexto mais geral das relações entre sociedade, tecnologia e meio ambiente. Parte-se de duas hipóteses principais: a primeira é que uma nova dimensão da produção capitalista da natureza vem transformando consideravelmente as relações sociais com o mundo natural nas últimas décadas; a segunda é que uma parte considerável do planeta vem sendo confrontada com uma rigorosa escassez de água. A perspectiva de que aqui se parte para testar essas hipóteses é a que vem sendo chamada de ecologismo dos pobres. Em termos metodológicos, o estudo sobre a crise da água - considerada um problema não apenas natural, mas sócio-ecológico se apoiou nos métodos histórico e estatístico. Os resultados indicam, de um lado, que as relações sociais com o mundo natural vêm, de fato, sendo transformadas pela produção capitalista da natureza nos últimos decênios; mas, de outro, que a hipótese de uma rigorosa escassez de água não se sustenta. O que parece haver é apropriação privada de água, com o emprego de tecnologias avançadas, para a realização de polpudos lucros. A contrapartida é o acesso restringido de parcelas consideráveis da população mundial à água para a satisfação de suas necessidades básicas. 
Palavras-chave: Água; Meio Ambiente; Sociedade; Tecnologia.

\begin{abstract}
The main purpose of this article is to analyze the problem of water in the overall framework of relations among society, technology and the environment. The two main hypotheses are: first, a new dimension of the capitalist production of nature has been changing the social relations with the natural world considerably in the last decades; second, large parts of the planet are faced with a severe water shortage. The general perspective from which these hypotheses are examined is that of the environmentalism of the poor. In methodological terms, this study on the water crisis - considered not strictly as a natural problem, but as a socioecological one - is supported by historical and statistical methods. The results indicate, on the one hand, that the social relations with the natural world are being transformed by the capitalist production of nature over the last few decades; however, on the other hand, the hypothesis of a severe shortage of water cannot be sustained. In fact, there is private ownership of water and the use of advanced technologies to realize large profits. In contrast, significant portions of the world population have restricted access to water to satisfy their basic needs.
\end{abstract}

Keywords: Environment; Society; Technology; Water.

\title{
Introdução
}

O tema da água, que se examina nas páginas a seguir, tem sido tratado com intensidade crescente. São distintos os aspectos enfatizados, os pressupostos, os enfoques, os interesses (nem sempre explicitados). Aqui se toma a água - sem trocadilho! - como meio essencial à vida em geral. Por isso, nenhum ser humano deveria ser excluído de sua fruição. Aceita-se que a água se destina ao abastecimento humano, assim como ao uso para dessedentação $^{2}$ de animais, irrigação, geração de energia elétrica, navegação, pesca e aqüicultura, fins industriais, recreação, turismo e lazer. Ela tem sido considerada um recurso social e um bem público. Mas, aos poucos, a água também vai sendo vista como 'meio de produção' e, por isso, 
requisito para a economia e para o desenvolvimento (HOERING, 2006; RIBEIRO, 2006).

Neste artigo se tem a preocupação de analisar o tema no contexto mais geral das relações entre sociedade, tecnologia e meio ambiente, partindo-se de duas hipóteses principais: a primeira é que uma nova dimensão da produção capitalista da natureza transformou consideravelmente as relações sociais com o mundo natural nas últimas décadas (SMITH, 2007) - hipótese que parece confirmar-se; a segunda é que uma parte considerável do planeta está confrontada com uma rigorosa escassez de água (ROSEGRANT et al., 2002) - hipótese que as evidências parecem rejeitar.

Há, evidentemente, diversas possibilidades de se examinar problemas sócio-ecológicos. A perspectiva de que se parte aqui tem sido chamada de 'ecologismo dos pobres' (e também de ecologismo popular, movimento de justiça ambiental e ecologia da libertação). Ela se apóia num "interesse material pelo meio ambiente como fonte de condição para a subsistência; não em razão de uma preocupação relacionada com os direitos das demais espécies e das futuras gerações de humanos, mas, sim, pelos humanos pobres de hoje" (ALIER, 2007, p. 33-34).

Portanto, o objetivo que se tem com esta intervenção é examinar, criticamente, a suposta crise da água - um problema não apenas 'natural', mas 'sócio-ecológico' - no contexto da transformação das relações sociais com o mundo natural da perspectiva do ecologismo dos pobres. Para cumprir esse intento dividiu-se o texto em cinco seções: além desta (i) introdução, incluem-se, ainda, as seguintes seções: (ii) a situação da água, ontem e hoje; (iii) a 'crise' da água; (iv) o Brasil no contexto da 'crise' da água; e (v) conclusões.

\section{A situação da água, ontem e hoje}

Quando se examina o tema da água, da água considerada essencial à vida, responsável pelo 'equilíbrio ambiental' e recurso insubstituível em inúmeras atividades humanas, imagina-se tratar de um 'bem' ilimitadamente disponível pela pródiga natureza que, presumidamente intacta, ainda cerca os grupos humanos e os espaços que estes habitam. De fato, a água considerada essencial à vida é acessível para consumo humano em limitadíssimo percentual: apenas $0,27 \%$ da água doce do planeta e apenas 
0,007\% do total de água existente no mundo estão, realmente, disponíveis para os fins antes mencionados. Evidente: essa quantidade de água seria suficiente para satisfazer as necessidades de toda a população mundial. Contudo, como se verá, a água está desigualmente distribuída - e acessível pelo planeta e tem sido progressivamente poluída - o que torna parcela crescente dela também indisponível (AZEVEDO; PEREIRA, 2006).

Como se chegou a esse ponto? Para compreender a situação presente convém voltar o olhar ao passado - que, de fato, pode oferecer evidências interessantíssimas a respeito do uso humano da água no contexto mais geral das relações entre sociedade, tecnologia e meio ambiente. Por exemplo, no mundo antigo, as cidades se tornaram, aos poucos, dependentes de água trazida de suas periferias por meio de aquedutos. As vilas mais distantes, porém, dependiam de riachos, ribeirões, lagos e poços - dos quais uma parte considerável da água era oportunamente canalizada para um templo ou um palácio próximo. A técnica de cavar poços foi aperfeiçoada por volta de 2200 a.C. Os egípcios aprenderam a obter água cavando túneis nas camadas inferiores do solo a partir do buraco principal de seus poços. Micenas foi a primeira cidade européia que logrou obter grandes volumes de água por um túnel subterrâneo. No entanto, foi apenas entre os séculos VII e VI a.C. que os aquedutos se tornaram parte integrante da paisagem.

Até o ano 312 a.C. os Romanos dispunham - a partir dos rios maiores, de algumas fontes e poucos poços - de água suficiente para seu abastecimento. Por volta do ano 97 a.C. Roma se tornara uma cidade de um milhão de habitantes, que dispunha de nove grandes aquedutos, cujo comprimento total alcançava cerca de $400 \mathrm{~km}$, que transportavam 450 litros de água por dia/per capita. Era, sem lugar a dúvida, uma quantia absurdamente alta de água consumida numa época como aquela. Em comparação com cidades européias modernas, Londres, Frankfurt e Paris consumiam, no ano de 1823, cerca de 3,6 litros de água por dia/per capita; no ano de 1936, as mesmas cidades consumiam cerca de 45 litros de água por dia/per capita! Não custa lembrar que um quinto de toda água consumida por Roma nessa época ia para a fruição do Imperador, e dois quintos abasteciam a cidade - inclusive as 591 fontes de água e dúzias de banhos públicos. Restavam, portanto, dois quintos para o uso privado - mas, mesmo aí, o consumo era desigual... (ILLICH, 1987).

A água também teve grande importância no cotidiano das comunidades camponesas e das populações que viviam em meio urbano 
antes do surgimento do capitalismo, incluindo o seu uso para diversas aplicações e técnicas. Um exemplo é o das rodas de moinho, que serviam não apenas para moer grãos como também para impulsionar serras, forjas e foles. No meio rural, a água era utilizada principalmente para irrigar a terra e como bebida para os animais. Os camponeses podiam criar certos tipos de peixes se tivessem acesso à água. Portanto, a ocorrência de secas era problemática, ameaçando sua própria existência. Mais tarde, a água passou a ser empregada no transporte a longa distância e na construção de diques e represas, visando à geração de energia (CONTI, 1986).

Por volta do final do século XVIII e início do século XIX, em muitas localidades do interior da Inglaterra e da França, mais da metade da população nunca chegou a tomar sequer um banho até a morte! Bem, ao nascerem, os bebês eram lavados, mas depois os humanos eram banhados novamente apenas após a morte. Por volta de meados do século XIX, os ricos constituíam o grupo social mais perfumado; os indivíduos que integravam a classe média eram reconhecidos pelo tanto que se escovavam e lavavam; e a desodorização da empobrecida maioria da população européia se tornara um objetivo de campanhas de educadores e da saúde pública - na época, uma espécie de 'polícia médica' [medizinische Polizei]. Apenas em 1880 é que principia a instalação de um 'quarto de banhos' no interior das casas burguesas. Três procedimentos distintos passam a confluir para este espaço das moradias: o banho, propriamente; a limpeza do corpo; e o vestir-se para o dia ou a noite. Com o tempo, o mesmo espaço passou a abrigar funções de toilette e - exclusivamente para os homens - de barbear. Este quarto de banhos, incorporando inúmeras tecnologias velhas, adaptadas e algumas novas, passa a ser provido de água corrente! Essas inovações iniciaram por volta de 1750 , tiveram acréscimos importantes por volta de 1850, mas apenas em 1950 se generalizaram a ponto de, então, entre 20\% a 30\% das casas européias incorporarem essas facilidades (ILLICH, 1987).

Ao longo da história, a água foi uma substância que traduzia pureza condição que perde com a ascensão da ciência moderna e o advento do capitalismo industrial. A ciência moderna desmistifica a água, convertendo-a num recurso técnico para prover soluções industriais. Neste novo contexto ela passa a ser $\mathrm{H}_{2} \mathrm{O}$ - que, ao invés de purificar, precisa ser purificada para assegurar $\bigcirc$ abastecimento humano. $O$ capitalismo industrial também desmistifica a água: $\mathrm{H}_{2} \mathrm{O}$ é um produto da economia capitalista moderna que 
requer um tratamento técnico-industrial, suscitando inúmeras contradições no âmbito das relações entre sociedade, tecnologia e meio ambiente.

\section{A crise da água}

A assim denunciada crise da água é uma crise que emerge da forma como este recurso essencial à vida foi convertido em 'meio de produção', em requisito para a economia capitalista. Ela pode ser compreendida a partir de seis aspectos que vêm chamando crescente atenção e, por isso, induzindo atores sociais influentes a falar numa 'rigorosa escassez de água para uma parte considerável do planeta'. Um primeiro aspecto, já referido, diz respeito ao fato de que a disponibilidade de água doce é cada vez mais limitada. Um segundo aspecto, também já mencionado, indica que sua distribuição geográfica é bastante desigual - mas, sobretudo, seu acesso vai se tornando brutalmente desigual. Outro aspecto corresponde ao desperdício de água, já demasiadamente alto. Outro aspecto, também já referido, concerne à crescente poluição da água. Um quinto aspecto é relativo à inadequada gestão da água. Por último e, provavelmente, mais importante, é o fato de que a escassez resultante dos cinco aspectos anteriores compromete dramaticamente o acesso à água (HOERING, 2001).

É pelo menos desde janeiro de 1992, quando ocorreu a Conferência Internacional sobre Água e Meio Ambiente ${ }^{3}$, em Dublin [Irlanda], que um novo 'paradigma' passou a governar a política da água. A partir daí a água passou a ser progressivamente subordinada a princípios econômicos e a ser convertida ela mesma em recurso econômico. Essa deveria ser a condição assim se passou a entender - para que a água pudesse vir a ser utilizada de maneira mais eficiente, melhor conservada enquanto recurso escasso, tornada mais acessível para quem dela necessita, ecologicamente melhor preservada (HOERING, 2006).

Ao longo dos anos 1990, após a Conferência de Dublin, surgiram diversos fóruns para debater a 'crise mundial da água'. Entre estes se destacam (HOERING, 2001):

- World Water Council [WWC], criado em 1996, reunindo governos, organizações internacionais e setor produtivo privado;

- Global Water Partnership [GWP], também criado em 1996, reunindo os mesmos atores do WWC e algumas ONGs; 
- World Commission on Water [WCW], criado em 1998, composto por 21 personalidades de todo o mundo, encarregada de elaborar uma world water vision 2020.

Em todos os fóruns citados, o Banco Mundial [BM] aparece como um global player de primeira grandeza - seu vice-presidente para programas especiais chegou a ser presidente do GWP. Mas, o setor produtivo privado não ficaria atrás: Suez e Vivendi, duas das maiores empresas francesas, e do mundo [ver tabela a seguir], estavam nesses fóruns devida e estrategicamente representados... Esses atores e fóruns empurraram o tema da água para outro grande fórum, a World Trade Organization - afinal, a água se tornara um recurso econômico! (HOERING, 2001).

Vale a pena fixar-se, por um instante, no BM: se até o final dos anos 1980 esta instituição apoiava governos no financiamento e gestão do setor água, incluindo a ampliação da infra-estrutura hídrica para diversos fins como, por exemplo, a geração de hidroeletricidade - desde 1993 ela mudou decididamente de enfoque. Daí em diante, e pioneiramente, o BM passou a formular uma concepção integrada de water resources management ${ }^{4}$, fundada nas seguintes recomendações de política (HOERING, 2005; idem, 2006):

- Uma reforma abrangente do arcabouço político-institucional do setor água: na nova configuração o Estado, com outras funções e, sobretudo, o setor produtivo privado e o conjunto de usuários assumiriam maior importância;

- Uma descentralização também abrangente do setor - por exemplo, até alcançar o nível de municípios: essa descentralização deveria ser complementada por investimentos na infra-estrutura hidráulica, ao nível dos municípios, para assegurar o abastecimento de água;

- A introdução de instrumentos econômicos na regulação da água enquanto bem comercializável no mercado, incluindo direitos de uso: na prática, isso levaria à privatização da gestão e do abastecimento de água.

Chama atenção a necessidade da retirada do Estado de funções estratégicas da regulação da água de meados dos anos 1990 em diante em comparação com o que eram suas atribuições até então. De fato, desde a segunda metade dos anos 1990, com a providencial mão visível do BM, em muitos países foram sendo realizadas reformas mais ou menos abrangentes do setor água. Na caixinha de ferramentas utilizada para viabilizar essas reformas se encontravam instrumentos econômicos orientados para o 
mercado - incluindo redução de custos e elevação de preços, logrados com o concurso de investimentos privados, aumento da concorrência e introdução de direitos de uso (HOERING, 2006). Na condição de principal fonte de crédito para governos de muitos países, o BM tem conseguido, sem maiores dificuldades, converter sua estratégia - a imposição das mencionadas reformas mais ou menos abrangentes do setor água - em políticas efetivas. Segundo Uwe Hoering (2006), o BM já assinou contratos no âmbito do country water resources assistance strategies [CWRAS] com pelo menos 14 países.

Além das recomendações do $\mathrm{BM}$, os vários fóruns criados ao longo dos anos 1990 e seus principais atores têm se preocupado também em estabelecer direitos de água e aperfeiçoar a sua gestão, incentivar o aumento da eficiência no uso da água na agricultura, melhorar a qualidade da água - o que significa despoluí-la - e pesquisar os efeitos das mudanças climáticas sobre os recursos hídricos [RH] (ROSEGRANT; RINGLE, 2004). Essas preocupações podem atrair investimentos privados para o setor água como deseja o BM. Contudo, mesmo se convertidas em políticas, elas não conduzirão, automaticamente, para um aumento de eficiência, a redução do desperdício, uma maior sustentabilidade ambiental e o atendimento da demanda dos pobres (HOERING, 2005).

Aqui, como em outros contextos, o BM, os poderosos fóruns da água e os atores sociais mais influentes se valem de uma retórica quase catastrofista para alardear que a crise da água ameaça a produção de alimentos, a saúde humana, a nutrição e o meio ambiente. Contudo, em conformidade com os interesses que defendem, recomendam investimentos altamente seletivos em tecnologia de ponta e infra-estrutura e medidas que incrementem a conservação e o uso eficiente de água. Esses investimentos e medidas, atente-se, requerem reformas na gestão da água, ou seja: reformas no aparato político-institucional - como propostas pelo $\mathrm{BM}^{5}$ - e rapidamente se esquece o que a crise da água parece ameaçar...

Quem ganha e quem perde com a política de comodificação, precificação, privatização e comercialização da água? As evidências têm mostrado que os global players do abastecimento privado de água é que são os grandes ganhadores [ver tabela 1 a seguir]. Os governos, em contrapartida, vêm acumulando dívidas no setor. Dentre os usuários, as demandas estão mais que asseguradas para quem têm como pagar pela água (HOERING, 2001). 


\begin{tabular}{|c|c|c|c|}
\hline Empresas & $\begin{array}{l}\text { Faturamento } \\
\text { [bilhões US\$] }\end{array}$ & $\begin{array}{c}\text { Lucros } \\
\text { [milhões US\$] }\end{array}$ & $\begin{array}{l}\text { Clientes } \\
\text { [milhões] }\end{array}$ \\
\hline Générale des Eaux / Vivendi & 12 & n.d. & 110 \\
\hline Suez / Lyonnaise des Eaux & 8,5 & 1.950 & 110 \\
\hline Thames Water / RWE [GB/D] & 4 & 1.400 & 43 \\
\hline SAUR / Bouygues [F] & 2,2 & 108 & 30 \\
\hline Severn Trent [GB] & 1,3 & n.d. & 20 \\
\hline $\begin{array}{l}\text { United Utilities / US Water } \\
\text { [GB/USA] }\end{array}$ & 1,2 & n.d. & 27 \\
\hline $\begin{array}{l}\text { American Water Works } \\
{[\mathrm{USA}]}\end{array}$ & n.d. & n.d. & 10 \\
\hline Anglian Water / AWG [GB] & 1,1 & 439 & 9 \\
\hline Azurix / Enron [USA] & 1 & n.d. & 4 \\
\hline E.on / Gelsenwasser [D] & 0,2 & n.d. & 4 \\
\hline
\end{tabular}

Fonte: Hoering (2001, p. 16).

Tabela 1 - Maiores firmas de abastecimento de água do mundo

Entre os atores que mais se beneficiam da nova política da água do BM estão, portanto, as novas empresas de gestão da água - como Suez e Vivendi, mas também Coca-Cola, Nestlé, Danone AQUA... [ver boxes 1 e 2]; as grandes empresas de construção civil; as instituições financeiras, inclusive, bancos comerciais privados; firmas de consultoria; governos, apesar das mudanças de atribuições; engenheiros, técnicos e administradores ativos nessas empresas; assim como, no meio urbano, indústrias intensivas em água que voltam parte de sua produção para camadas de médias e altas rendas ou para o mercado externo; e na área rural o agronegócio, não menos consumidor de grandes volumes de água, que baseia sua produção na monocultura de exportação.

\section{Box 1}

Danone AQUA é uma empresa do grupo Danone que atua na Indonésia e lá explora vários mananciais de água potável na Ilha de Java - apoiado pelo CIRAD, uma rede francesa de transferência de tecnologia [www.cirad.fr]. A seguir, trechos de entrevista com Yann Brault, responsável pela área de desenvolvimento sustentável e responsabilidade social da Danone AQUA.

P: quais são as atividades da sociedade Danone AQUA?

R: na Indonésia, o mercado de água em garrafa ou galão [de 19 litros] é muito importante. Danone AQUA explora 11 mananciais por todo o país e engarrafa água em 13 plantas. A cada ano, Danone AQUA vende cinco bilhões de litros de água. O setor de águas aromatizadas está em desenvolvimento. 
[...]

P: como reconciliar a exploração comercial de uma fonte subterrânea e a gestão integrada dos $\mathrm{RH}$ ?

R: em primeiro lugar, efetuamos um preciso diagnóstico hidrogeológico dos recursos para evitar a sobre-exploração do aqüífero. Mas, para uma exploração sustentável, é necessário também que as comunidades locais compartilhem uma visão comum do desenvolvimento. Utilizamos um enfoque participativo com o fim de associar os distintos usuários da água aos processos de decisão sobre a gestão dos recursos: eles decidem conjuntamente as ações que devem realizar-se.

P: como proteger a qualidade da água dos mananciais explorados?

R: Danone AQUA explora águas subterrâneas de montanha [...] As plantas de engarrafamento contam com o certificado ISO 14.000. Estamos, pois, diante de uma água de qualidade e para conservá-la, Danone AQUA estabelece programas de proteção dos recursos: reflorestamento das zonas de recarga, agricultura integrada e gestão dos resíduos... ("Partenarios" Danone AQUA, em Valorisation \& Innovation em Partenariat, CIRAD, N. 8, jan. 2007, p. 4) [traduzido do espanhol].

\section{Box 2}

Outros exemplos da crescente relevância econômica da água em nível internacional: o caso Coca-Cola em Kerala/Índia e o caso Nestlé ["pure life"] em Minas Gerais/Brasil são exemplos de ampliação do controle da água pelo setor produtivo privado para fins de produção de bebidas; a produção mineral - no Chile, no Brasil... - também oferece exemplos de como a água controlada localmente pelo setor produtivo privado ganha mercados globais (ZIMMERLE, 2005).

Entre os atores que perdem estão os pobres e os defensores do meio ambiente, a começar pelas comunidades de camponeses e pequenos produtores rurais que voltam sua produção para o mercado interno; os moradores das periferias urbanas, não apenas dos países periféricos, mas também do mundo desenvolvido; além dos pequenos produtores formais e informais das cidades que não têm acesso a tecnologias adequadas para aumentar sua eficiência no uso de água... Uns e outros têm seu abastecimento de água ameaçado.

Em março de 2006, a Cidade do México foi palco do mais recente confronto sobre a crise da água no planeta. De um lado, o já citado WWC organizou, nesta cidade, o IV Fórum Mundial da Água. De outro, a Coalizão de Organizações Mexicanas pelo Direito à Água [COMDA], com o apoio de um conjunto amplo de organizações, coletivos e redes internacionais, organizou de 17 a 22 de março de 2006, o Foro Internacional em Defesa da Água, contraponto à comodificação, precificação, privatização e comercialização da água - como defendido pelo WWC (RODRIGUEZ, 2006). 


\section{O Brasil no contexto da crise da água}

Pode-se inscrever a condição específica do Brasil no contexto mais geral da alardeada 'crise mundial da água'? Para responder a essa questão convém caracterizar a atual situação da água no Brasil, mas também examinar as mudanças recentes pelas quais passou o aparato político-institucional do setor água, a relevância deste recurso essencial à vida à luz de diversos casos concretos, e sua especialíssima situação na Amazônia.

\section{A situação da água no Brasil, hoje}

Comparando-se sua distribuição pelos continentes, pode-se afirmar que "a América Latina e o Caribe possuem a maior disponibilidade hídrica per capita [30.925 $\mathrm{m}^{3} / \mathrm{hab} / \mathrm{ano}$ ] do mundo [...] contribuindo para 31\% da água doce do mundo". No contexto continental, "o Brasil encontra-se numa posição mais confortável, pois possui $36.580 \mathrm{~m}^{3} / \mathrm{hab} / a n o^{\prime}$. Todavia, essa água está mal distribuída: $73,2 \%$ concentram-se na região da bacia amazônica, na qual vivem menos de $5 \%$ da população brasileira (AZEVEDO; PEREIRA, 2006).

Para atender aos principais usos consuntivos ${ }^{6}$ há uma necessidade mínima de 2.058 litros de água/habitante/dia. Para os demais usos [nãoconsuntivos] - navegação, hidroeletricidade, piscicultura, lazer... - são utilizados outros 2.590 litros de água/habitante/dia. De forma que a demanda de água no Brasil alcança a marca de 4.650 litros/habitante/dia (CHRISTOFIDIS, 2006).

\section{O aparato político-institucional}

Com uma disponibilidade dessas, as fontes brasileiras de água devem despertar desejos inconfessáveis nos empreendimentos que lidam com esse meio essencial à vida como recurso econômico. A necessidade de regular os apetites desembocou, também no Brasil, num novo aparato políticoinstitucional. A preocupação com a gestão dos RH foi contemplada, no Brasil, pela primeira vez, pelo Código de Águas de 1934. Alguns de seus dispositivos foram regulamentados apenas na Constituição Federal de 1988 [CF 1988]. A Lei das Águas [Lei No. 9.433/1997] passou a regulamentar o inciso XIX do artigo 21 da CF 1988. Entre outras coisas, ela define que (GALINDO 2007):

- A água é um bem de domínio público e recurso natural limitado, mas dotado de valor econômico [grifo meu]; 
- A bacia hidrográfica é a unidade do território na qual é feita a gestão $\operatorname{dos} \mathrm{RH}_{;}$

- Sua gestão deve contemplar o uso múltiplo e descentralizado, com a participação do poder público, dos usuários e da comunidade;

- Em nível nacional, a gestão dos RH é feita por um Sistema Nacional de Recursos Hídricos [SNRH], em nível local, por comitês de bacia.

O novo aparato político-institucional que, no Brasil, passou a ser responsável pela gestão da água envolve múltiplos atores. Aí se destacam o Poder Legislativo, incluindo o Congresso Nacional, as Assembléias Legislativas e as Câmaras de Vereadores; o Poder Executivo em nível federal, estadual e municipal; o Poder Judiciário, para o qual se canalizam os contenciosos; o Ministério Público; os integrantes do SNRH [ver figura 1 abaixo]; os especialistas e técnicos, a imprensa, as ONGs e os organismos comunitários; as fontes de financiamento e bancos; os usuários, desde industriais até irrigantes... (RIBEIRO, 2006).

\begin{tabular}{|c|c|c|c|c|c|}
\hline \multirow[b]{2}{*}{ Âmbito } & \multicolumn{2}{|c|}{ Formulação da política } & \multicolumn{3}{|c|}{ Implantação da política } \\
\hline & $\begin{array}{l}\text { Órgãos } \\
\text { colegiados }\end{array}$ & $\begin{array}{l}\text { Administração } \\
\text { direta }\end{array}$ & $\begin{array}{l}\text { Poder } \\
\text { outorgante }\end{array}$ & "Parlamento" & $\begin{array}{l}\text { Escritório } \\
\text { Técnico }\end{array}$ \\
\hline \multirow[t]{2}{*}{ Nacional } & $\mathrm{CNRH}$ & MMA & ANA & & \\
\hline & & SRH & & & \\
\hline Estadual & CERH & $\begin{array}{l}\text { Governo } \\
\text { Estadual }\end{array}$ & $\begin{array}{l}\text { Órgão } \\
\text { Estadual }\end{array}$ & & \\
\hline \multirow[t]{2}{*}{ Bacia } & & & & $\begin{array}{l}\text { Comitê } \\
\text { Bacia }\end{array}$ & \\
\hline & & & & & $\begin{array}{l}\text { Agência } \\
\text { da Bacia }\end{array}$ \\
\hline
\end{tabular}

Figura 1 - Sistema Nacional de Recursos Hídricos

Fonte: baseado em Mascarenhas (2006, p. 134) e Ribeiro (2006, p. 35).

Entre esses atores existe, sem lugar à dúvida, uma grande diversidade de percepções, interesses, valores, mentalidades, atitudes e comportamentos, níveis de conhecimento e informação, bem como 'acessos' ao poder político e econômico.

A tentativa de regular os apetites pelo controle da água no Brasil desembocou, pois, num novo aparato político-institucional, o SNRH 
[esquematicamente apresentado acima]. No entanto, a diversidade de atores que freqüentam o setor água implica (como, aliás, se mencionou) numa diversidade de percepções, interesses, valores... - que, aqui como alhures, parece confluir para uma compreensão da água enquanto recurso econômico. E essa compreensão parece produto da hegemonia exercida por certos atores no âmbito do novo aparato político-institucional do setor água. E essa configuração do $\mathrm{SNRH}$, em que certos atores logram imputar à água um valor econômico, parece ter uma origem bem definida... Ou será que o BM não conseguiu convencer os brasileiros da relevância da água?

\section{A relevância da água no Brasil: alguns exemplos}

Era previsível que o aparato político-institucional implantado no Brasil não dirimiria os conflitos que se avolumam no setor água. Pelo contrário, novos conflitos seriam fatalmente chamados à superfície - pela óbvia razão de que o SNRH se confrontaria com o fato de que a água vai sendo convertida, cada vez mais, num recurso econômico. Evidências que o ilustram já abundam, de maneira que se pode, com a referência a exemplos selecionados, demonstrar que a água se tornou, também no Brasil, demasiadamente importante.

Exemplo 1 - a falta crônica de água no balneário de Guaratuba, no estado do Paraná, com pouco mais de 30 mil habitantes fixos, levou à evasão de turistas - que chegam a 1,4-1,6 milhão/temporada - e a pesadas perdas econômicas; para encaminhar uma solução para o 'problema' foram realizados esforços, envolvendo o governo japonês [Japan Bank for International Cooperation], o Banco Interamericano de Desenvolvimento, o governo federal brasileiro [via Caixa Econômica Federal], o governo estadual [via SANEPAR] e a administração pública municipal; com os investimentos realizados e a correspondente ampliação da oferta de água, esperava-se recuperar os turistas perdidos (MENDES et al., 2007).

Exemplo 2 - a região de Campinas, localizada na bacia hidrográfica do Rio Piracicaba, no estado de São Paulo, com 2,152 milhões de habitantes, altamente industrializada, tinha uma disponibilidade de água correspondente a 3,22 $\mathrm{m}^{3} / \mathrm{s}$ e uma demanda estimada de 1,73 m³ $/ \mathrm{s}$ em 1996 - o que representava 54\%; os usos industriais e domésticos [estes, por parte de uma classe média afluente] levaram a que em 2004 essa relação passasse a ser de $72 \%$; se mantido o ritmo de crescimento no consumo da água, impulsionado pelo 'dinamismo' da economia regional e pelo aumento da camada da população de rendas médias e altas, prevê-se, na virada da 
década, que dita relação alcance 100\% (PEREIRA; KIMMELMANN E SILVA, 2004).

Exemplo 3 - além de se prestar a usos consuntivos e não-consuntivos conhecidos, a água tem se revelado também como importante elemento de projetos urbanísticos e saneamento ambiental; é o caso em Belém, no estado do Pará, em que sobressaem um projeto bancado pela prefeitura daquele município [Portal da Amazônia] e outro pelo governo estadual [Mangal das Garças]; ambos se baseiam na idéia de que a cidade pode projetar imagens que reflitam a preocupação com a preservação do meio ambiente e com a identidade cultural; de fato, porém, ambos os projetos parecem instrumentalizar a água para fins de lazer e apelo turístico: a natureza é apropriada para propiciar benefícios aos que podem dela fruir nas novas circunstâncias estético-urbanísticas (PONTE, 2007).

Exemplo 4 - dado que a água é recurso indissociável do meio natural, ela tanto é afetada quando os ecossistemas são degradados como ela pode afetá-los negativamente quando se a polui e usa de forma inadequada; desmatamentos para desenvolver pecuária extensiva no Estado do Acre já alcançam a maior parte da área de preservação permanente ao longo dos rios; neste caso, os ecossistemas degradados impactam o ciclo hidrológico, provocando secas e enchentes; de fato, situações de seca extrema e queimadas têm se repetido, assim como aumentos da pluviosidade; os resultados se traduzem em enchentes cada vez mais de graves - como as de 1988 e 1997; esta última gerou 18 mil desabrigados (RODRIGUES; TORRICO, 2007).

Os exemplos referidos parecem indicar que, a despeito das tentativas de regulação inauguradas com o novo aparato político-institucional, a água vai se tornando importante, sobretudo, em virtude de vir se tornando, cada vez mais, alvo de disputas econômicas. Se bem que a legislação brasileira e o próprio SNRH propiciassem condições para que a população, ao nível das bacias hidrográficas, passasse a participar da gestão da água, esses instrumentos também podem continuar favorecendo os atores sociais dominantes. Em outras palavras: o que parecia constituir um mecanismo de intervenção da sociedade organizada na gestão descentralizada da água pode, por ironia, facilitar o acesso privilegiado e a apropriação dos $\mathrm{RH}$ por parte dos que detêm o poder político e econômico em nível local (ABERS; KECK, 2006). 
Se, no Brasil, a sociedade organizada tivesse condições de exercer controle mais rigoroso da água nas diversas escalas, duas preocupações deveriam ganhar maior relevância. Em primeiro lugar, políticas públicas adequadas deveriam ser orientadas para a provisão à população do país de um sistema de esgotamento sanitário e reuso dos $\mathrm{RH}$. Aqui, pois, a água tem importante função, não cumprida, de assegurar a saúde pública. Seu descumprimento até o presente é motivo de agravamento das condições sociais de vida da população carente e de gastos elevados com internações hospitalares decorrentes de moléstias associadas à falta de esgoto sanitário (ALMEIDA et al., 2002). Em segundo lugar, ignoram-se, ainda, quase por completo, as implicações geopolíticas da água - e não se trata apenas da especialíssima situação da bacia amazônica [ver a próxima sub-seção]. O Aqǘffero Guarani é o maior manancial de água doce subterrânea transfronteiriço do mundo, ocupa uma área de 1,2 milhões de $\mathrm{km}^{2}$ e ocorre em quatro países. No Brasil, concentram-se $71 \%$ ! - na Argentina são $19 \%$, no Paraguai são $6 \%$ e no Uruguai são $4 \%$, respectivamente. Não apenas os esforços dos quatro países - em particular, do Brasil - para protegerem esse "bem comum" são tímidos: não parece haver qualquer proibição ou limitação ao acesso de potências estrangeiras para 'pesquisar' o tema e se aproximar perigosamente desse objeto de desejo de empresas - e governos estrangeiros (GUIMARÃES, 2006; ZIMMERLE, 2005).

\section{A relevância da água no Brasil: a especialíssima situação da Amazônia}

As implicações geopolíticas da água parecem ser ignoradas também em relação à especialíssima situação da bacia amazônica. Com efeito: quando se fala em Amazônia, trata-se da maior floresta tropical úmida do mundo, cuja área total alcança aproximadamente 7 milhões de $\mathrm{km}^{2}$, o que representa cerca de $56 \%$ das florestas tropicais do planeta. O rio Amazonas e seus afluentes, que cortam toda a floresta, representam a maior bacia fluvial da Terra, respondendo por cerca de $20 \%$ do total de água doce que adentra os oceanos do planeta. Aqui se percebe melhor como se inter-relacionam água e ecossistema: alterações nos ecossistemas da bacia amazônica podem provocar impactos na circulação atmosférica, no transporte de umidade para e da região e, conseqüentemente, no ciclo hidrológico, não apenas da América do Sul, mas de diversas partes do planeta (CORREIA et al., 2007).

De formas pouco sutis, o capitalismo industrial vem se impondo, mais aceleradamente nos últimos decênios, tanto sobre as formas precedentes de 
organização social quanto sobre os modos como as comunidades locais se relacionam com o meio natural.

"A água é essencial à vida e o peixe está entre as fontes fundamentais de proteína que permitem a vida humana na Amazônia. A abundância da água e do peixe, aliada à facilidade de seu aproveitamento, contribuíram decisivamente para viabilizar milênios de ocupação, orientando os aldeamentos à beira dos rios e locais piscosos [...] em particular nas últimas décadas, o caráter universalizador do modo de ser da sociedade industrial vem introduzindo uma competição desigual com as populações desfavorecidas em torno ao aproveitamento da água e do peixe. A frente econômica compromete a renovabilidade dos recursos vitais ao escolher a rentabilidade imediata" (LEONEL, 1998, p. 23).

São inúmeras as atividades que têm degradado de forma brutal o meio natural - impactando sobremaneira os $\mathrm{RH}$ - e afetado as formas de organização das comunidades do interior e as localizadas nas periferias urbanas da Amazônia. Dentre tais atividades se destacam o empresariamento da pesca (que compete com a pesca artesanal e a autodeterminação do pescador beiradeiro e ribeirinho), a extração mineral, a garimpagem e o uso do mercúrio, a exploração da madeira e a ação predatória das madeireiras, as hidrelétricas e a ação das grandes construtoras, o próprio processo colonizador não planejado, amparado na expansão urbana e industrial, e a agropecuária:

"A agropecuária promove o desmatamento das nascentes, várzeas, margens de rios, dos igarapés e dos lagos, criando barragens e aterros de acesso, atingindo o habitat, perturbando o ciclo reprodutivo da ictiofauna e sua nutrição, dependente da floresta inundada e das várzeas" (LEONEL, 1998, p. 24).

Contudo, se até recentemente a água na Amazônia era tida como abundante e de uso ilimitado, aos poucos se passa a considerá-la como recurso escasso, economicamente valioso, em torno do qual se vão estabelecendo novos conflitos. Se antes os ecossistemas iam sendo degradados e, assim, ameaçando os RH em nível local, agora a água vai sendo compreendida, cada vez mais, como importante recurso econômico. Convém lembrar que, contrariamente ao uso predatório dos recursos dos ecossistemas amazônicos - dos hídricos, sobretudo - perpetrado pelos atores socialmente mais influentes, 
"O uso diferenciado dos recursos naturais pelas sociedades das florestas tropicais é um modo de ser e de ver diferente, não apenas um conjunto de técnicas isoláveis, mais ou menos sofisticadas. O elo é a integração em que se encontram com os outros seres, resultando em uma dimensão maior dos limites, pela intimidade com o ambiente" (LEONEL, 1998, p. 220).

A situação da água na Amazônia, assim como das comunidades locais e do meio natural, parece destinada a continuar recebendo atenção menor que a merecida. A despeito dos supostos esforços para regular a água naquela (sob todos os possíveis aspectos) estratégica bacia, a sua condição tem despertado pouco mais que indiferença.

\section{(In)conclusões}

A preocupação subjacente a este artigo era a de tratar do tema da água no contexto mais geral das relações entre sociedade, tecnologia e meio ambiente. O objetivo, propriamente, era de examinar, de forma crítica, a suposta crise da água - um problema que se considerou não apenas 'natural', mas 'sócio-ecológico' - no contexto da transformação das relações sociais com o mundo natural da perspectiva do ecologismo dos pobres. Chegado a este ponto, pode-se aceitar que o tema, como proposto, foi devidamente tratado; e que o objetivo, como formulado, foi em algum grau alcançado. Todavia, que conclusões se podem extrair desse exame da água, meio essencial à vida em geral que, segundo se buscou mostrar, foi se convertendo em recurso econômico? Quaisquer afirmações relativas à questão da água estão condicionadas por duas perguntas: Primeira, dado o quadro que se acabou de esboçar, é possível fazer (tanto de um ponto de vista técnico quanto político) alguma coisa? Aliás, tem sido feito alguma coisa? Segunda, quais são os constrangimentos objetivos que se interpõem entre o que existe, resultado da imposição dos interesses econômicos dos atores sociais influentes, e o que deveria emergir, da perspectiva dos imperativos sócio-ecológicos que assegurariam um acesso justo e ambientalmente prudente aos $\mathrm{RH}$ ?

Quanto à primeira pergunta, é preciso fortalecer as comunidades locais, mas, subsidiariamente, construir/dispor de respaldos políticos e legais nas demais escalas para o exercício de um efetivo controle social sobre a água. A tarefa inicial é política, pois. No entanto, simultaneamente, é preciso realizar 
"uma análise dos lençóis profundos e das águas da superfície, que avalie a capacidade anual das precipitações, que registre o consumo, os usos, o escoamento. O reconhecimento dos recursos hídricos deve servir de base aos planos regionais, que devem se inspirar no critério de manter a água circulando o maior tempo possível, favorecendo assim a reciclagem e os usos múltiplos" (CONTI, 1986, p. 25).

Inúmeras iniciativas, em diversos cantos do planeta, fundadas no fortalecimento da sociedade civil organizada, empregando tecnologias relativamente simples, têm logrado controlar o uso da água para garantir o seu acesso equitativo aos integrantes das comunidades locais. Entre variados exemplos de uso social e ambientalmente adequado da água destacam-se (HOERING, 2001, p. 35):

- Um sistema relativamente barato de abastecimento de água em Karachi [Paquistão], que atende a 600 mil pessoas, resultou de iniciativas de apoio mútuo das famílias antes privadas de seu acesso;

- Um sistema de abastecimento e canalização de água, acessível à população de baixa renda, foi estruturado na localidade de La Sirena, em Cali [Colômbia], a partir do engajamento espontâneo de moradores locais;

- Um sistema de consumo comunitário foi construído para propiciar o acesso da população pobre de Mezquital, na periferia de Guatemala, à água provida pela rede pública daquela municipalidade;

- Sistemas de coleta e tratamento de água da chuva, em inúmeras localidades no interior da Índia, garantem acesso (sobretudo, às comunidades rurais) da água, tanto para fins domésticos como para a agricultura.

A possibilidade da difusão de iniciativas como as listadas, que apontem para o controle social dos $\mathrm{RH}$ (e um acesso justo e ambientalmente prudente) depende, em larga medida, dos constrangimentos impostos pelos interesses econômicos dos atores sociais mais influentes nas diferentes escalas em que a água é disputada - o que conduz à segunda pergunta. Em outros termos: é possível fazer alguma coisa - e, como se viu, muito já vem sendo feito. Mas, não se pode esquecer que, como

"a orientação geral do desenvolvimento cabe às grandes empresas, o uso dos recursos não renováveis faz-se em função de um horizonte temporal relativamente curto [...] o poder de que dispõem as empresas no sistema capitalista é suficientemente grande - geração de poupança, orientação da inovação técnica, manipulação dos consumidores - para que elas possam 
enquadrar a reprodução do sistema econômico-social de maneira a evitar modificações significativas..." (FURTADO, 1977, p. 111).

A mesma lógica que subjaz à atuação da grande empresa em geral, que orienta o processo de desenvolvimento em geral, também tem impregnado os atores que se movem no interior do setor água. $\mathrm{O}$ uso dos $\mathrm{RH}$, como, em geral, dos recursos naturais, é governado pelo curto prazo: a água se tornou 'meio de produção', requisito para a economia e para o processo de acumulação. De forma que poucas dúvidas devem restar que a natureza tem sido mais e mais integrada ao capital como estratégia de acumulação - o que confirma a hipótese de que as relações sociais com o mundo natural foram transformadas consideravelmente pela produção capitalista da natureza nas últimas décadas (SMITH, 2007).

Entretanto, por isso (pelo fato de o capitalismo integrar a natureza, com todos os seus 'recursos', inclusa aí a água, subordinando-a aos interesses da grande empresa e dos atores sociais mais influentes), precisamente por isso, a segunda hipótese - de que uma parte considerável do planeta está confrontada com rigorosa escassez de água (ROSEGRANT et al., 2002) - não se sustenta. O que há é apropriação privada de água, com o emprego de tecnologias avançadas, para a realização de lucros no melhor estilo do laissez-faire do século XIX. Em conseqüência, parcelas consideráveis da população mundial têm tido acesso restrito à água para a satisfação de suas necessidades básicas.

Que outra tarefa mais relevante resta que não a de re-politizar a questão da água? E que outro sentido tem a re-politização da água senão a luta permanente por sua completa descomodificação?

\section{Notas}

${ }^{1}$ Este artigo resulta de intervenção realizada na mesa redonda "tecnologia e desenvolvimento sustentável", realizada no âmbito do II Simpósio Nacional de Tecnologia e Sociedade, promovido pelo Programa de Pós-Graduação em Tecnologia/UTFPR, que teve lugar em Curitiba, aos 7 de novembro de 2007.

${ }^{2} \mathrm{O}$ termo dessedentação é corrente nos debates sobre demanda da água. O prefixo des nega o radical sedento. O verbo dessedentar significa, pois, 'saciar a sede'.

${ }^{3}$ Ver WORLD METEOROLOGICAL ORGANIZATION. International conference on water and the environment: development issues for the 21st century (the Dublin statement). Geneva: WMO, 1992 [disponível em http://www.wmo.ch/web/homs/documents/english/icwedece.html].

4 Ver WORLD BANK. Water resources management (= World Bank Policy Paper). Washington/DC: World Bank, 1993. 
5 É óbvio que esses atores têm pressa, talvez para solver a crise da água, mas mais provavelmente para desencadear rapidamente bons negócios. Como admitem Rosegrant et al. (2002, p. 206), "these solutions are not easy, and will take time, political commitment, and money. One thing is certain: the time do act on fundamental reform of the water sector is now". ${ }^{6} \mathrm{O}$ termo consuntivo é corrente nos debates sobre demanda da água. Trata-se de uma variação de consumptivo e se refere a três usos principais da água: produção de alimentos, produção industrial e abastecimento humano.

\section{Referências}

ABERS, R. N.; KECK, M. E. The erratic partner in Brazil's participatory water policy. Anais do III Congresso da Associação Latino-americana de Ciência Política. Campinas: UNICAMP, 2006.

ALIER, J. M. 0 ecologismo dos pobres: conflitos ambientais e linguagens de valoração. Tradução: M. Waldman. São Paulo: Contexto, 2007.

ALMEIDA, F. G. et al. Importância estratégica da água para o terceiro milênio.

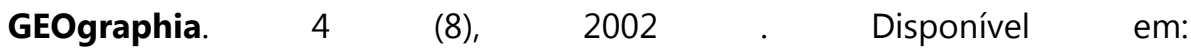
http://www.uff.br/geographia/rev_08/flavio8.pdf

AZEVEDO, L. G. T.; PEREIRA, J. M. G. Água no mundo. Plenarium [Especial: "os múltiplos desafios da água"], Ano III, Número 3, p. 10-18, setembro de 2006.

CIRAD. "Partenarios" Danone AQUA. Valorisation \& Innovation en Partenariat. N. $\quad 8, \quad$ p. 4 , janeiro-2007 Disponível em: http://www.cirad.fr/fr/prest_produit/pdf/vip/vip8_es.pdf

CONTI, L. Ecologia: capital, trabalho e ambiente. São Paulo: Hucitec, 1986.

CORREIA, F. W. S. et al. Balanço de umidade na Amazônia e sua sensibilidade às mudanças na cobertura vegetal. Ciência e cultura. Ano 59, N. 3. p. 39-43, jul.-set. 2007.

CHRISTOFIDIS, D. Água e agricultura. Plenarium [Especial: "Os múltiplos desafios da água"], Ano III, Número 3, p. 44-59, setembro de 2006. 
FURTADO, C. Prefácio à nova economia política. 2. ed. Rio de Janeiro: Paz e Terra, 1977.

GALINDO, E. F. Gestão hídrica articulada à gestão territorial: entre a retórica e a prática. In: Anais do XII Encontro da ANPUR. Belém, 21-25 mai. 2007.

GUIMARÃES, L. R. Aqüífero Guarani: integração e destaque da América Latina no cenário mundial. Anais do III Congresso da Associação Latinoamericana de Ciência Política. Campinas; UNICAMP, 4-6 set, 2006.

HOERING, U. Privatisierung im Wassersektor: Entwicklungshilfe für transnationale Wasserkonzerne - Lösung der globalen Wasserkrise? Bonn: World Economy, Ecology and Development, 2001.

HOERING, U. Wasser für Nahrung, Wasser für Profit: Die Politik der Weltbank im landwirtschatlichen Sektor (Hintergrund-Materialien, 15). Stuttgart: Brot für die Welt, 2005.

HOERING, U. Der Markt als Wassermanager: Aufbau eines neue Wasserregimes durch die Weltbank. Peripherie. Ano 26, N. 101/102, p. 2142, 2006.

ILLICH, I. $\mathbf{H}_{\mathbf{2}} \mathrm{O}$ und die Wasser des Vergessens. Reinbeck bei Hamburg: Rowohlt, 1987.

LEONEL, M. A morte social dos rios: conflito, natureza e cultura na Amazônia. São Paulo: Perspectiva; IAMA, 1998.

MASCARENHAS, A. C. Comitê de bacia hidrográfica: o que é, como funciona, e que papel desempenha na gestão de recursos hídricos. Plenarium [Especial: "Os múltiplos desafios da água"], Ano III, Número 3, p. 134-145, setembro de 2006.

MENDES, J. M. G. et al. Abastecimento de água em Guaratuba: economia regional, redes e territorialidade. Anais do XII Encontro da ANPUR. Belém, 21-25 mai. 2007. 
PEREIRA, S. Y.; KIMMELMANN E SILVA, A. A. Availability and consumption of groundwater resources in the Campinas region, SP, Brazil. TERRAE. 1 (1), 3443, 2004.

PONTE, J. P. X. Cidade e água: Belém/PA e estratégias de reapropriação das margens fluviais. Anais do XII Encontro da ANPUR. Belém, 21-25 mai. 2007.

RIBEIRO, M. A. Hidratando a gestão ambiental. Plenarium [Especial: "os múltiplos desafios da água"], Ano III, Número 3, p. 30-43, setembro de 2006.

RODRIGUES, E.; TORRICO, R. Águas do Acre. Anais do XII Encontro da ANPUR. Belém, 21-25 mai. 2007.

RODRIGUEZ, S. A. Agua: ¿derecho humano o mercancía? los Foros del Agua en México. Cuadernos del CENDES. 23 (61), p. 175-181, 2006.

ROSEGRANT, M. W.; RINGLER, C. Five priorities for water policy reform. IFPRI Forum. p. 8-9, março-2004.

ROSEGRANT, M. W. et al. World water and food to 2025: dealing with scarcity. Washington/DC: International Food Policy Research Institute, 2002. SMITH, N. Nature as accumulation strategy. Socialist Register. p. 16-36, 2007.

WORLD BANK. Water resources management (World Bank Policy Paper). Washington/DC: World Bank, 1993.

WORLD METEOROLOGICAL ORGANIZATION. International conference on water and the environment: development issues for the 21st century (the Dublin statement). Geneva: WMO, 1992. Disponível em: http://www.wmo.ch/web/homs/documents/english/icwedece.html

ZIMMERLE, B. Es geht nicht nur um Dienstleistungen: Der Griff nach der Ressource Wasser (Hintergrund-Materialien, 14). Stuttgart: Brot für die Welt, 2005. 